\title{
AN ENGINE RESEARCH PROGRAM FOCUSED ON LOW PRESSURE TURBINE AERODYNAMIC PERFORMANCE
}

\author{
Raymond Castner \\ NASA Glenn Research Center \\ John Wyzykowski \\ Pratt \& Whitney Canada \\ Dr. John Adamczyk \\ NASA Glenn Research Center
}

Santo Chiappetta

Pratt \& Whitney Canada

\begin{abstract}
A comprehensive test program was performed in the Propulsion Systems Laboratory at the NASA Glenn Research Center, Cleveland Ohio using a highly instrumented Pratt and Whitney Canada PW 545 turbofan engine. A key objective of this program was the development of a high-altitude database on small, highbypass ratio engine performance and operability. In particular, the program documents the impact of altitude (Reynolds Number) on the aero-performance of the lowpressure turbine (fan turbine). A second objective was to assess the ability of a state-of-the-art CFD code to predict the effect of Reynolds number on the efficiency of the lowpressure turbine. CFD simulation performed prior and after the engine tests will be presented and discussed.
\end{abstract}

Key findings are the ability of a state-of-the art CFD code to accurately predict the impact of Reynolds Number on the efficiency and flow capacity of the low-pressure turbine. In addition the CFD simulations showed the turbulent intensity exiting the low-pressure turbine to be high $(9 \%)$. The level is consistent with measurements taken within an engine.

\section{INTRODUCTION}

It is well known that the aero-performance (adiabatic efficiency) of the low-pressure turbine (LPT) of a turbofan engine decreases with altitude or Reynolds number. This reduction in aero performance is commonly referred to as Reynolds number lapse.

This is a preprint or reprint of a paper intended for presentation at a conference. Because changes may be made before formal publication, this is made available with the understanding that it will not be cited or reproduced without the permission of the author.
A number of studies (Halstead, et al. (1997); Hodson, (1990), LaGraff and Ashpis, (1997) suggest that the boundary layers on LPT blading transitions towards a laminar flow state as Reynolds number is reduced. Thus for a fixed level of aerodynamic loading a reduction in Reynolds number can result in flow separation. If the separated flow regions are large the efficiency of the LPT will be compromised. Having a flow model, which can accurately predict the Reynolds number lapse of a LPT is key to the execution of successful designs. This is of particular importance today because of the emphasis on reducing design time and reducing LPT blade count without sacrificing LPT efficiency. In addition the recent interests in Uninhabited Aerial Vehicles (UAV) for high altitude surveillance has added even more emphasis on the need for models that can accurately predict the LPT Reynolds number lapse in efficiency.

The work in this paper outlines a test program in which aero-performance data is acquired for an LPT turbine operating in an engine environment over a range of Reynolds number typical of a UAV application. The engine used in this test is a Pratt \& Whitney Canada (PWC) PW 545 jet engine. The PW 545 engine is a highbypass engine with a thrust rating of $3000 \mathrm{lbs}$. The LPT turbine in the PW 545 engine has three stages. This engine was highly instrumented in order to determine the Reynolds number lapse in efficiency of the LPT. CFD simulations were preformed using the CFD code APNASA, Adamczyk et.al. (1990) prior to the tests. These 
simulations established the ability of a state-of-the-art CFD code to predict the Reynolds number lapse of the LPT efficiency. Results from simulations executed after the tests will also be presented. These post-test simulations further support the ability of the CFD code to accurately estimate the Reynolds number lapse of the LPT efficiency.

\section{Engine Test Set-up}

The PW 545 High Altitude Test was performed in the NASA Glenn Research Center Propulsion Systems Laboratory, Cell 4. An overall installation sketch of the test engine installation is shown in Figure (1).

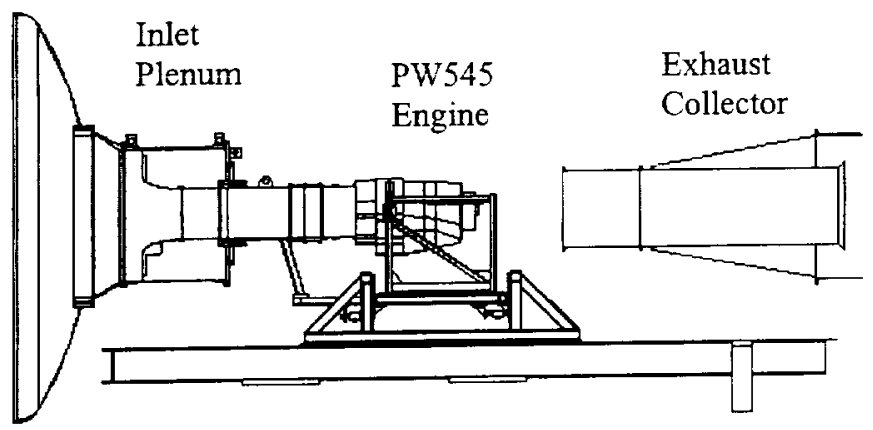

Figure 1 - PW 545 in PSL4

The test engine, a PW 545 turbofan, was hard-mounted via engine stand to a single-axis thrust stand. The metric bed is designed to accommodate the PWC engine stand, and also support the inlet ducting. One measurement and one calibration load cell are included on the stand. An onboard hydraulic cylinder and hand pump is used to calibrate the stand prior to all testing. The engine was built, instrumented, and acceptance tested in a sea level test facility in Mississauga, Ontario, Canada and flight tested on the PWC Boeing B720 Flying Test Bed (FTB).

The flow capacity of the test cell ranges from $250 \mathrm{pps}$ to 400 pps at a typical inlet pressure of 4 psia. For these tests the inlet flow was reduced to 12 pps at an inlet pressure of 1.13 psia. The low flow rates required for this test program, relative to what is typical, necessitated additional inlet instrumentation. The station 1.0 instrumentation duct (Figure 2.) provided mounting for four boundary layer rakes, one cross-duct rake, and wall static instrumentation ports. The cross-duct rake was used to verify the total pressure profile at the duct inlet as measured by the boundary layer rakes. The forward edge of the duct was the metric break location for the entire inlet assembly.

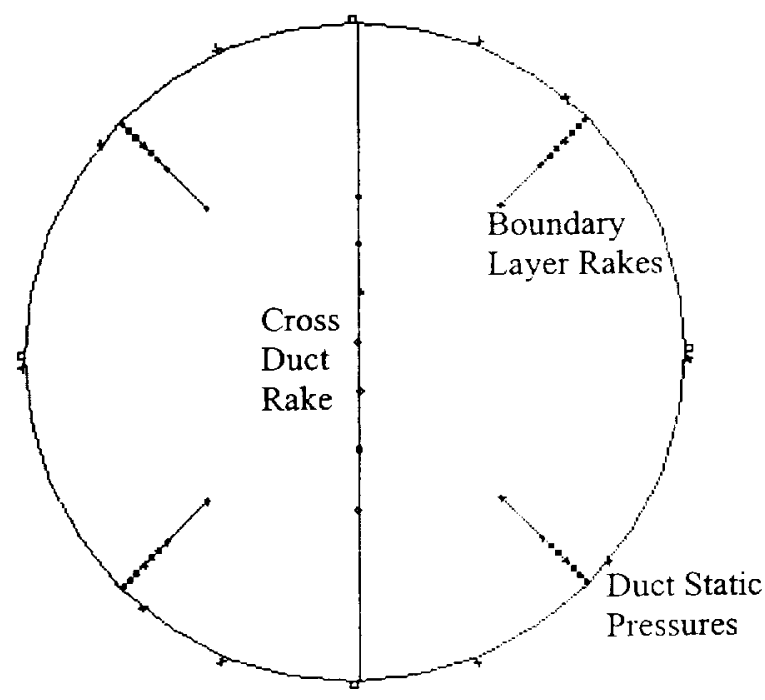

Figure 2 - PW 545 Station 1.0 Instrumentation

Six thermocouple rakes with 12 elements each were installed near station 1.0 to measure the incoming total temperature profile. The station 2.0 duct mounts directly to the engine compressor inlet case. Four boundary layer rakes were installed at this location to record the total pressure profile and airflow at this location. The measurement accuracy of the incoming engine mass flow was estimated to be better than $1 \%$.

\section{Turbine Measurements}

For this test program the LPT was heavily instrumented to record the lapse in turbine performance with Reynolds number. Over 150 pressure and temperature sensors were installed in the LPT module. The LPT instrumentation plus the instrumentation in the fan and core compressor were used to infer the incoming flow conditions to the LPT (corrected flow) and its efficiency. The accuracy of the efficiency estimates derived from the data was $+/-1$ point.

\section{Test and CFD Simulation Results}

Prior to the engine tests CFD simulations were performed at four Reynolds numbers. The rotation speed of the LPT was fixed at a corrected speed parameter of 280 . This speed parameter is defined as the physical rotational speed (rpm) of the LPT divided by the square root of the total temperature (measured in Degs. Rankine) of the gas stream entering the LPT. The inlet flow conditions specified in the simulations (total temperature, total pressure, flow angles, and turbulence level) were provided by Pratt and Whitney Canada. 
The CFD simulations were performed using the APNASA code, Adamczyk et al. (1990). The APNASA code solves the average passage equation system as formulated by Adamczyk (1985). This equation system governs the time average flow field within a typical passage of a blade row embedded in a multistage axial flow turbomachine.

The turbulence model used by APNASA in this study is an enhanced $\mathrm{k}-\varepsilon$ model (CMOTT turbulence model) developed by Shih et al. (1995) modified to be consistent with the average passage equation system. The uses of this turbulence model in CFD simulations of turbomachinery is reported upon by Shabbir et al. (1996), Adamczyk et al. (1998). The CMOTT turbulence model does not explicitly account for transition. As reported by Adamczyk et al. (1998) the model appears to provide reasonable estimates of the aero performance of axial flow compressors in flow regimes where the flow is known to be in transition.

The CFD simulations performed prior to the engine tests incorporated models for purge flows and leakage about the rotor tip knife-edge seals (all rotors are tip shrouded). The predicted normalized efficiency lapse with Reynolds number is shown on Figure (3). The Reynolds number is defined in terms of the chord of the first LPT vane, and the flow conditions at midspan at the exit of the vane. The simulations span a large range of Reynolds number ranging from 30,000 to 295,000 . The efficiency estimates derived from the CFD simulations used mass averaged inlet and exit flow values of total temperature and total pressure. In addition the efficiency estimates explicitly accounted for leakage and purge flows.

\section{Normalized Efficiency vs Reynolds Number}

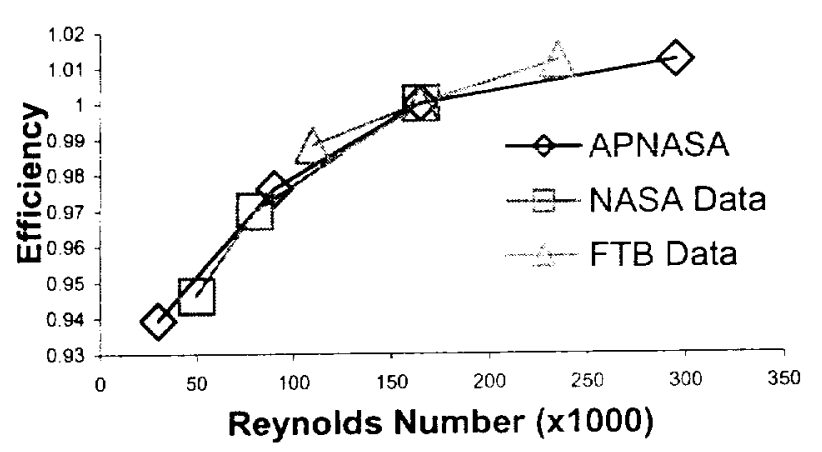

Figure 3

The corresponding experimental results derived from the engine tests at NASA Glenn are shown on the figure. This data ranges from a Reynolds number of 50,000 to 165,000 . In addition efficiency estimates derived from a fight test bed (FTB) program have also been included. The Reynolds numbers for the fight test program range from 110,000 to 235,000 . All efficiency estimates (engine results are not a direct measurement) have been normalized by their respective value at a Reynolds number of 165,000 . Thus all results have a value of one at Reynolds number of 165,000 .

Figure (3) shows that the Reynolds number efficiency lapse as predicted by the CFD simulations is in very good agreement with that deduced from the engine data. From a Reynolds number of nearly 300,000 to 30,000 the CFD simulation predicts nearly a 7 percent reduction in efficiency. The predicted lapse is well within the accuracy of the efficiency estimates derived from engine data.

The next figure shows the lapse in LPT inlet corrected flow with Reynolds number. Once again CFD simulation results as well as results derived from both engine tests (Tests at NASA Glenn, and fight test bed) are shown. All inlet corrected flow estimates have been normalized with respect to their value at a Reynolds number of 165,000. All estimates show a well defined trend, and are self consistent with each other. Once again the CFD results are well within the accuracy of the flow rate estimates derived from the engine test data. 


\section{Normalized Inlet Corrected Flow vs Reynolds Number}

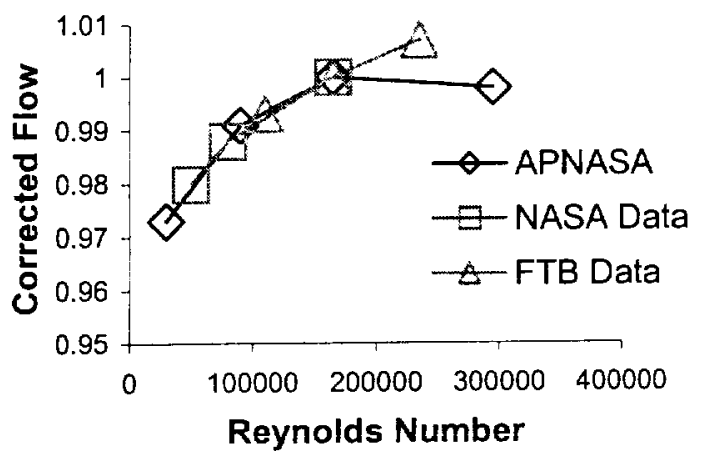

Figure 4

At the start of the CFD simulation exercise questions arose as to the dependency of the simulation results on the values specified for purge and leakage flow rates. It was hypothesized that the value for efficiency is highly dependent upon the values set for these flow rates but that the Reynolds number efficiency lapse is a weak function of these flow rates. This was the case irrespective of whether the efficiency estimates were derived from CFD results or engine tests data. To establish the validity of this hypothesis a series of CFD simulations were performed without purge and leakage flows. These CFD simulation results are shown in Figure (5) along with the results from Figure (3). Once again the efficiency results are normalized as outlined above. With the exception of the results at the lowest Reynolds number, the Reynolds number efficiency lapse for this engine is a weak function of the purge and leakage flow rates.

\section{Normalized Efficiency vs Reynolds Number, Fixed Corrected Flow}

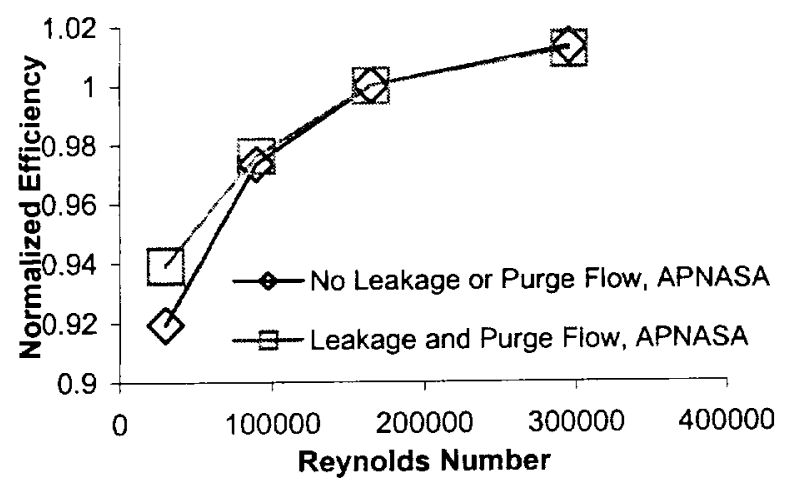

Figure 5
Figure (6) shows lapse in inlet corrected flow with Reynolds number, both with and without purge and leakage flows. The results show that the dependence of the lapse of inlet corrected flow on Reynolds number is a weak function of the leakage and purge flows.

\section{Normalized Inlet Corrected Flow vs Reynolds Number, Fixed Corrected Speed Parameter}

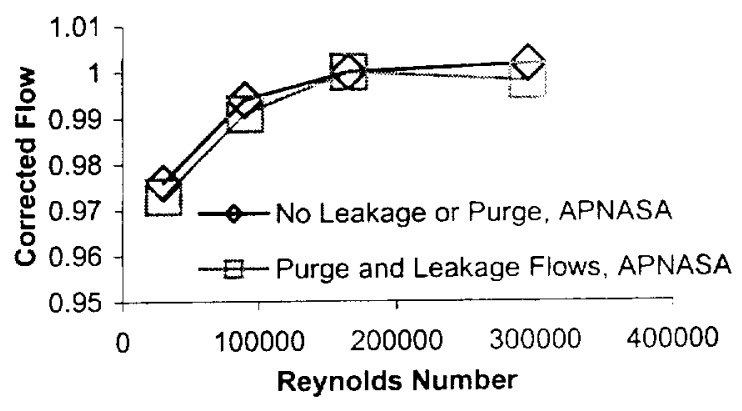

Figure 6

Based on the results presented in Figures (5) and (6) all additional CFD simulation results to be presented will not include the effect of purge and leakage flows.

A second set of CFD simulations were generated (executed after the engine tests was completed) at a speed parameter of 250 . These simulations were executed in order to compare with engine data for Reynolds numbers below 50,000 . Four simulations were done ranging from a Reynolds number of 25,000 to 135,000 . Results from this second set of simulations are shown in Figure (7). This time the efficiency has been normalized with respect to the efficiency at a Reynolds number of 135,000 . Efficiency estimates derived from engine data are also shown. These results have also been normalized with respect to their value at a Reynolds number of 135,000 . The range of the engine results is from 30,000 to 135,000 . 
Normalized Efficiency vs Reynolds Number at Corrected Speed of $\mathbf{2 5 0}$

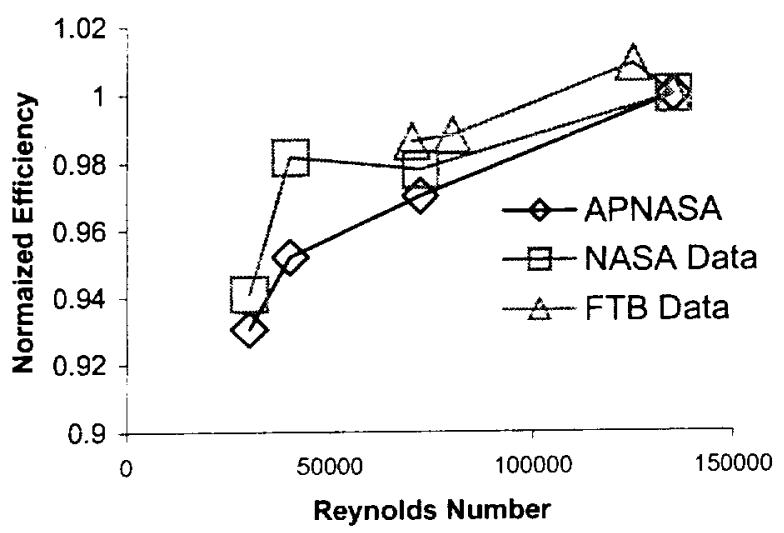

Figure 7

This time the correlation between engine data and CFD results is not as clear as that on Figure (3).

There is even a lack of correlation between the estimates derived from the two sets of engine test data.

However, if one neglects the estimate at a Reynolds number of 40,000 derived from the tests at NASA Glenn there is good agreement between estimates derived from the CFD simulations and those derived from the tests at NASA Glenn. Given that the estimates derived from the engine tests data have an error of plus or minus one point one could also state that the CFD based estimates are in reasonable agreement with those derived from the FTB study.

The CFD simulations provided a creditable estimate of the efficiency lapse of the LPT with Reynolds number. Based on these simulations an estimate of the dependency of entropy rise across the LPT on Reynolds number was attempted. The results are shown in figure (8) in which the log of the entropy rise across the LPT is plotted as a function of the log of the Reynolds number. A reasonable fit to the simulation results is a linear curve whose slope is -0.274 . This dependence of entropy rise across the LPT on Reynolds number lies between that for a laminar flow $(-0.5)$ and that for a fully turbulent flow $(-0.2)$.
Log of Entropy Rise vs Log of Reynolds Number

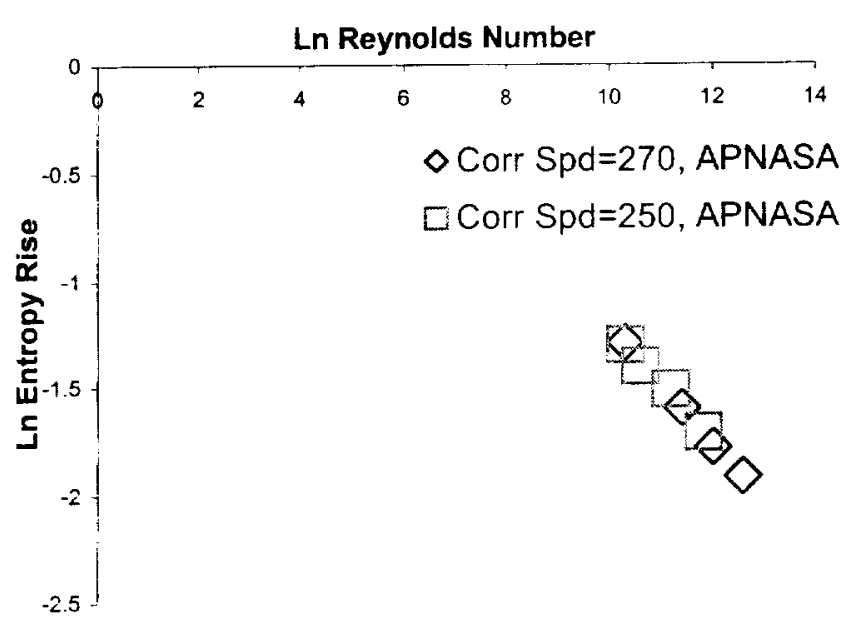

Figure 8

Key to the ability of APNASA to predict the efficiency lapse of the LPT with Reynolds number is capturing the turbulence level through the LPT. The turbulence level is defined in terms of turbulent intensity as:

$$
\mathrm{I}=\sqrt{2 k / 3} / q
$$

where $k$ is the axi-symmetric average of the turbulent kinetic energy, and $q$ is the axi-symmetric average of the absolute velocity. A plot of the turbulent intensity at midspan at various axial locations within the LPT is shown in Figure (9).

Turbulence Level Through LPT

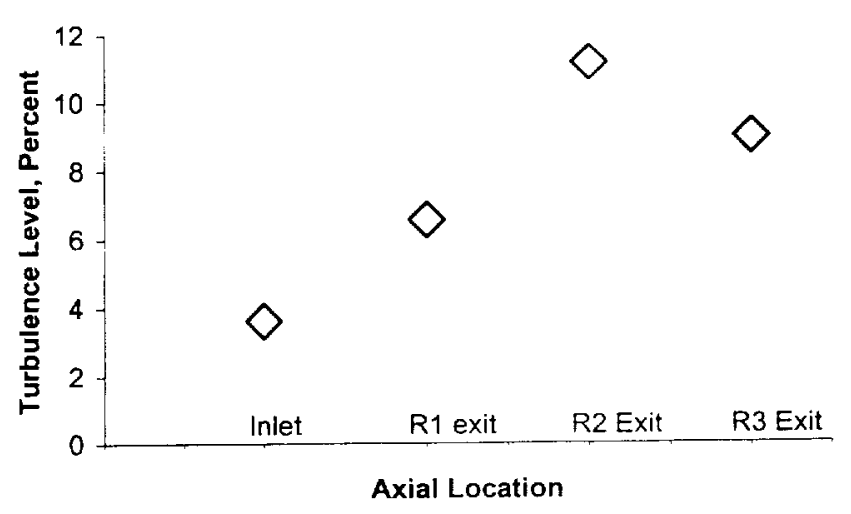

Figure 9 
These values are derived from the CFD simulations for a Reynolds number of 295,000 , which corresponds to Sea Level Take-Off conditions. The results show the turbulent intensity increases through the first two stages of the LPT but decreases slightly across the last stage. The decrease is the result of a reduction in the aerodynamic loading of the last stage relative to the second stage.

Figure (9) shows that the turbulence intensity is more than doubled between the inlet and the exit of the LPT. Sharma (1998) reported measurements of turbulent intensity downstream of a LPT at Sea Level Take-Off conditions ranging from $12 \%$ to $16 \%$. The turbulent intensity derived from the CFD simulation is not out of line with the measurements reported by Sharma (1998). The high level of turbulence intensity aft of the first stage raises issues as to the nature of the transition process in the inner stages of a LPT.

\section{Conclusions}

A comprehensive engine research program was conducted to establish the Reynolds number efficiency lapse of an LPT under engine operating conditions. In support of this engine research program a series of CFD simulations were preformed to establish the ability of a CFD code (APNASA) to predict the Reynolds number efficiency lapse as well as the lapse in LPT inlet corrected flow with Reynolds number. Both the CFD simulations and the engine tests points spanned a wide range of Reynolds numbers, which makes the current study important.

The CFD simulation results presented in this paper capture the lapse in aerodynamic efficiency with Reynolds number quite well. It also appears the CFD simulations accurately capture the lapse in LPT inlet correct flow with Reynolds number. CFD simulations show that the effect of leakage and purge flow on the efficiency lapse and inlet corrected flow lapse is small.

The CFD simulations were executed using a turbulence model that does not explicitly account for flow transition. The model does however account for the production of turbulence due to the straining of wakes as they convect through a blade row. It is the straining of wakes that leads to an increase in turbulence intensity through the LPT. The model also accounts for the damping of turbulent kinetic energy near solid surfaces, the extent of which increases as the Reynolds number is reduced. The high turbulence level of the free stream penetrates the outer region of the blade boundary layers to a depth established by the wall-damping model. The resulting state of the boundary layer thus determines its response to an imposed pressure gradient. These key elements of the turbulence model play a key role in generating the results presented in this paper.

\section{References}

Adamczyk, J.J., 1985, "Model Equation for Simulating Flows in Multistage Turbomachines," ASME paper 85-GT226.

Adamczyk, J.J.,Celestina, M.I., Beach, T.A., and Barnett, M., 1990,"Simulation of Three-Dimensional Viscous Flow within a Multistage Turbine", Trans. ASME, 112,370-376.

Adamczyk, J.J., Hathaway, M.D., Shabbir, A., and Wellborn, S.R., 1998,"Numerical Simulationof Multistage

Turbomachinery Flows," Presented at the Vehicle Technology Symposium onDesign Principles and Methods for Aircraft Gas Turbine Engines, hosted by AGARD in Toulouse, France May 11-15, 1998.

Halstead, D.E., Wisler, D.C., Okiishi, T.H., Walker, G.J., Hodson, H.P., and Shin, H., 1997,"Boundary Layer Development in Axial Compressors and Turbines Part 1 of 4: Composite Picture,"Journal of Turbomachinery, Vol. 119, p.114.

Hodson, H.P., 1990, "Modeling Unsteady Transition and Its Effects on Profile Loss," ASME Journal of Turbomachinery, Vol. 112, No. 4.

LaGraff, J.E., and Aships, D.E., 1998, "Minnowbrook II 1997 Workshop on Boundary Layer Transition in Turbomachines," NASA/CP-1998-206958

Shabbir, A., Zhu, J. and Celestina, M.L., 1996,"Assessment of Three Turbulence Models in a Compressor Rotor",ASME Paper No. 96-GT-198

Sharma, O.P., 1998,"Impact of Reynolds Number on LP Turbine Performance", NASAVP-1998-206958

Shih, T.H., Liou, W.W., Shabbir, A., Zhu, J. and Yang, Z., 1995, "A New k-e Eddy Viscosity Model for High Reynolds Number Turbulent Flows", Computers Fluids, 24, 3, 227 238. 